\title{
Analysis of the strain on employees in the retail sector considering work-life balance
}

\author{
Gert Zülch ${ }^{\mathrm{a}, *}$, Patricia Stock ${ }^{\mathrm{a}}$ and Daniel Schmidt ${ }^{\mathrm{a}}$ \\ ${ }^{\mathrm{a}}$ ifab-Institute of Human and Industrial Engineering, Karlsruhe Institute of Technology (KIT; formerly University \\ of Karlsruhe), Kaiserstrasse 12, Karlsruhe, Germany
}

\begin{abstract}
Many companies currently strive to support their employees' work-life balance through appropriate measures in order to improve employees' loyalty towards the company and to recruit new employees. In this context, flexibility in the area of working times is a measure that can influence employees' private lives immensely. This is why the individualisation of working time arrangements has been accorded high importance in current discussions on work-life balance. In this area, best practice examples can be found showing how working-time arrangements can improve the situation of the employees. It should be noted, however, that there is not one single perfect working-time model. A working-time model must always be adapted specifically to the actual situation of the company and the employees. Therefore, a targeted analysis of the challenges facing the company and the demands on the employees is essential for the creation of an appropriate working time policy. In particular, the employees' working-time preferences must be appropriately taken into account. Owing, however, to a combination of organisational complications and legal data protection restrictions, it is for the most part impossible to meet these working-time preferences in their entirety. This paper, which is based on an employee survey, illustrates the strain on employees in the retail sector and identifies different types of working-time preferences.
\end{abstract}

Keywords: Working-time configuration, work-life balance, retail stores

\section{Work-life balance as a competitive factor for companies}

The term "work-life balance" has become increasingly important over the past years. Many companies regard family-friendly policies as a competitive advantage, which is why work-life balance has developed into a strategic topic in many Human Resource departments. In the published work available, there are a great number of differing descriptions and explanations of the concept of work-life balance. Companies and other organisations most often associate it with the topic "work-family balance", which puts the emphasis on families. This definition, however, is not sufficient to explain the term comprehensively. In the context of this paper, work-life balance is used to indicate a holistic balance between private life and work.

In this, the term "work" stands for "working world". It comprises all activities, determining factors, roles, functions and structural conditions that can be put in relation to all aspects of work and profession.

The term "life" is to be understood as "private life" or "sphere of life outside of work". The latter term explicitly excludes the working world. This term "sphere of life outside of work", per definition, represents the opposite of the term of "working world". Thus, it comprises both activities occurring in private life, such as for example child care, housework, caring for relatives and recreational activities. The terms "sphere of life outside of work" or "life" consequently cover all areas existing outside of working world.

"Balance" stands for both objective and subjective distribution of time and priorities, where this is based on different criteria: balance may refer to the actual distribution of time as well as to subjective preferences. Here, both short-term - days or hours - and longer-term perspectives are possible. The term "balance" refers to the concept of a set of scales. The goal

\footnotetext{
* Corresponding author. Phone: ++49-721-608-44839, Fax: ++49-721-608-47935, E-mail: gert.zuelch@kit.edu.
} 
to be achieved is to balance both spheres of life. Yet this balance always depends on the individual person concerned, so that there is no absolute or universally valid determination of what the ratio of "work" to "life" should optimally be.

In reality however, the juxtaposition of "work" and "life" proves most of the time to be problematic, since it suggests that one's real life, that in which one strives to achieve self-fulfilment and self-actualisation, can only occur outside of the sphere of "work" the sphere to which the only purpose is the acquisition of money. Since the middle of the 1970s, the endeavour of work structuring is to achieve selffulfilment and self-actualisation in the working world, at least to a certain extent. The term "empowerment" represents this trend with the focus on the job.

\section{The importance of working time on work- life balance}

In current discussions on work-life balance and particularly in many service sectors - the transition to flexible working times are regarded as highly important. From the perspective of employees, flexible working times are essential for a good work-family balance [4, p. 8]. In Germany for example, $96 \%$ of working parents wish for flexible working times, particularly to accommodate emergency situations ([2], as cited in [4, p. 8]). Employees who are caregivers for relatives also need flexible working times in most cases [4, p. 9].

If designed appropriately, flexible working-time models offer numerous advantages for both company and employee which can lead to a "win-win" situation ([11, p. 58 and pp. 63], [4, p. 6]). Nevertheless, flexible working-time models can also have disadvantages, which typically are to the detriment of the employee concerned [11, p. 54].

In this context, the creation of appropriate working-time models is a decisive success factor for companies and employees (acc. to [4, p. 7]). Therefore in February 2011 the German Federal Government, the German trade associations and the Federation of German Trade Unions launched the initiative "family-conscious working times" with the goal to improve work-family balance [5].

The realisation of working-time models which appropriately support employees' work-life balance poses new challenges to companies, since, along with the concerns of employees, the interests of the company as well as the conditions of prevailing laws and collective bargaining agreements need to be taken into account (for more details refer to [11, pp. 52]). Research on this subject offers a number of best practice examples (for instance $[3,8,10,13,19]$ ) which, however, generally cannot be simply applied to other companies. What is more, reports on failed workingtime models tend not to be published. Consequently, currently available best practice examples can support individual companies only to a limited extent in their working-time planning. There is currently no set of tools available to evaluate the likely impact of a working-time model on work-life balance during the planning stages of the model.

\section{Analysis of the strain on employees in retail stores}

\subsection{The ARBWOL project}

The goal of the ARBWOL Project (German acronym for "working-time configuration in consideration of work-life balance") against this backdrop is to analyse the effects of flexible working-time models on work-life balance and the total picture of the demands on employees resulting from a specific model.

To this end, so-called social roles are identified within the heterogeneous group of employees, describing their position in their environment outside of work as well as the obligations and expectations resulting from these positions. In conjunction with the definition of these different social roles, typical strains and potential conflicts between private and working lives for each role are identified.

Appropriate working-time models may compensate for such strains and conflicts in line with the concept of work-life balance. The necessary data is collected from a written survey of employees in different service industries. The results will be used to deduct guidelines for actions and recommendations on how to design working-time models which reduce the overall strain on employees.

Two hospitals, one call-centre and two retail chains took part in this study as co-operation partners. The service sectors represented in this study are characterised by an especially high requirement for flexible working times. A survey of employees consisting of 2,700 individual questionnaires was distributed. The relatively high overall return rate of about $38 \%$ shows the importance of this topic for the employees. Due to the still running evaluation of all returned questionnaires, only the results from a single 
location - which accounted for around half of all answers - of one of the retail chains will be presented. For the results from the other companies, refer to [20] or [23].

This project is currently jointly supported by the German Federal Ministry of Education and Research and the European Social Fund (Support Code 01FH09046).

\subsection{Questionnaire for the employee attitude survey}

In the framework of this project, a questionnaire to investigate the demands on the employees from an employee perspective was developed. It is based on the existing questionnaire SALSA (German acronym for "Salutogenetic Subjective Work Analysis"; [14]). Contrary to other questionnaires for work analysis, which generally focus on the pathogeny of working conditions, SALSA mainly focuses on the conditions and protective factors which serve to maintain and promote health, referred to as resources [14, pp. 404]. Specifically interesting for the survey is that $S A L S A$ provides several standardised key figures for the service industry.

However, the primary focus of SALSA is the work sphere; this questionnaire dedicates only six questions to private life. Since this limited number of questions does not suffice for the analysis envisaged for the $A R B W O L$ project, the questionnaire was expanded through the addition of questions concerning the interplay between professional and private life according to Carlson et al. [7]. Furthermore, questions concerning the implemented working-time models as well as employees' preferences concerning their working time and their activities in their private lives were added.

\subsection{Demographic results}

In the retail chain examined, the questionnaires were handed out to around 1,200 employees, 593 of whom returned completed questionnaires, which gave a return rate of $49 \%$. Participation in the study was voluntary but the time used to fill in the questionnaire was recognised as working time. The proportion of women in the test sample was $96 \%$ and thus considerably higher than the proportion of women working in the German retail sector as a whole. In 2009 , women made up $71 \%$ of the approximately 2.1 million employees in the German retail sector, not including car dealerships and garages $[17$, p. 95]. The share of full-time employees in the sample was $36 \%$, slightly lower than in the German retail sector as a whole. The proportion of full-time employees in the German retail sector as a whole - again not including car dealerships and garages - was $42 \%$ [17, p. 407].

\subsection{Demands and strain on employees}

Concerning what is demanded on the employees and which strains they are under, SALSA provides standards both, for the working population in Germany as a whole and the service and production sectors in particular. Below, the SALSA standard for the service sector will be used for comparison.

The perceived demands (see Figure 1) all significantly deviate from the SALSA standard for the service sector. Completeness of tasks is significantly higher than the standard, which is to be seen as positive. Demands concerning qualification and responsibility, however, are as a whole below the respective standard, which is not unusual for the retail sector (cf. for instance [18, pp. 73]).

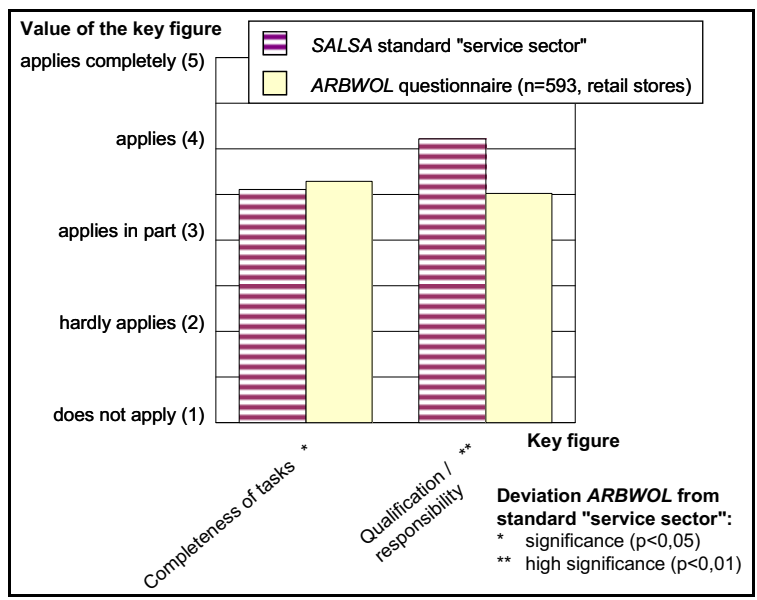

Fig. 1: Demands perceived by the employees

The perceived strains (see Figure 2) are all below the standard, meaning that the overall strain due to the demands on the employees is generally very low. It should be noted especially that the social climate is here less than in the standard. The strain caused by the working environment is perceived to be at a very low level. The greatest strains result from having to stand for long periods of time and having to deal with unpleasant customers. This was expected. However, with regards to perception, these strains are only perceived to be at a low to medium level. 


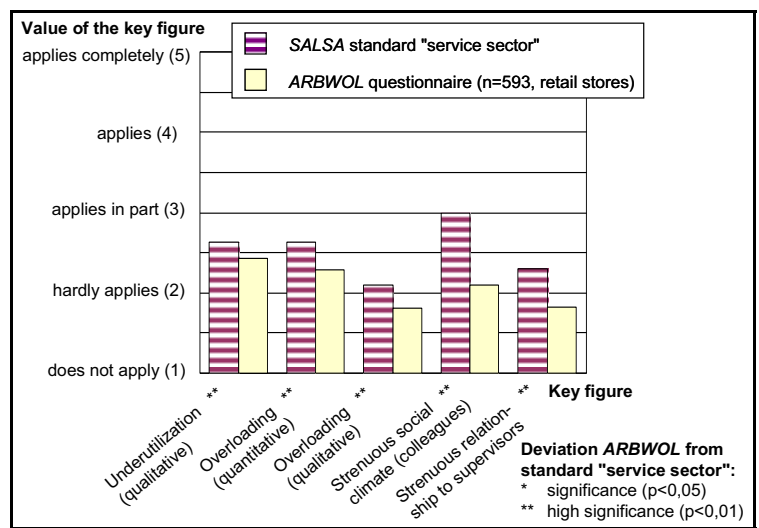

Fig. 2: Strains perceived by the employees

\subsection{Employees' organisational and social resources}

Organisational (see Figure 3) and social resources (Figure 4) protect and promote health and thus counteract the demands and strains in order to maintain or restore a person's health [14, pp. 404]. As opposed to the strains, here it is desirable that the value should be as high as possible.

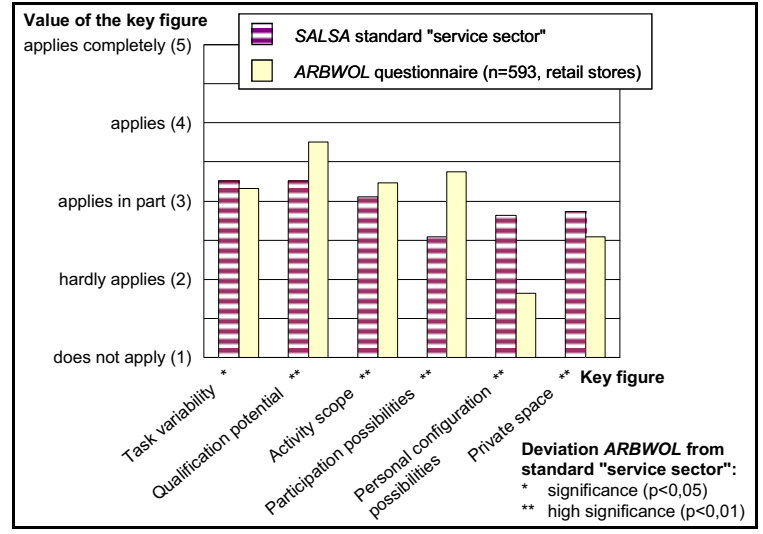

Fig. 3: Organisational resources perceived by the employees

All values referring to these resources deviate significantly from the standard. The relevance of the social resources is much higher than in the standards. This means that the social climate is not only not strain-inducing but generally beneficial for the employees. In contrast, one must differentiate in the analysis of the organisational resources: as expected, the variability of tasks, the individual possibilities to design one's workspace and the flexibility afforded to employees' personal and private spheres are below the standard.
This result is heavily influenced by the structural peculiarities of the retail sector, which allow particularly little room to manoeuvre. The values for the potential to achieve further qualifications in a specific job, the scope of the employees' daily duties and the possibilities to participate however, are, in part considerably higher than the standard, which should be regarded as positive.

Yet all in all, it should be noted that the relevance of the resources - even if they partly exceed the standard - is low, so that there is still potential for improvement.

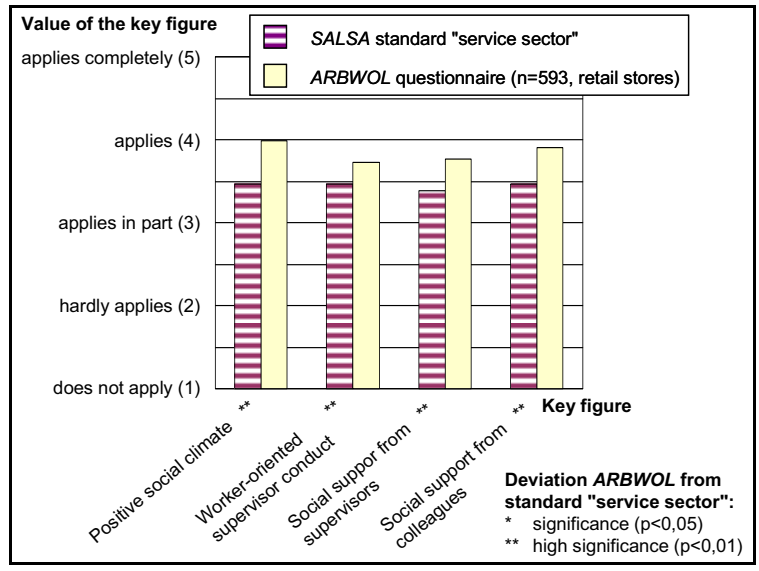

Fig. 4: Social resources perceived by the employees

\subsection{Interactions between work and private life}

Concerning the interaction between work and private life, Carlson et al. [7, p. 251] generally differentiate between two directions of conflict: "work interference with family" and "family interference with work". Moreover, they differentiate between three different types of conflict, namely "time based", "stress based" and "behavioural based". From this, six different key figures can be derived (see Figure 5), their numerical values ranging from 1 (meaning no relevance) to 5 (meaning strong relevance).

Generally, the key values are at a very low level, indicating that there are hardly any conflicts in these areas between the two spheres of life. However, it can be seen that the influence of work on private life is considerably higher than the reverse. One exception is the influence on behaviour: Behaviour at work is significantly more strongly influenced by behaviour in the private sphere of life than the other way around. 


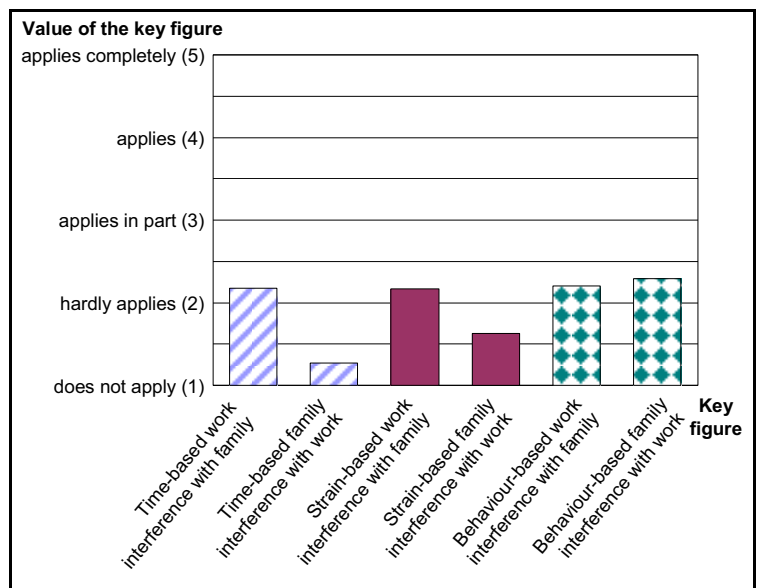

Fig. 5: Interactions between the employees' professional and private spheres of life (conflict directions according to [7])

\subsection{Assessment of working times}

The average working-time configurations for parttime workers and marginal part time workers include 17.3 hours, though the standard deviation for this average is a relatively high 9.5 hours. The average working time per working day is 3 to 6 hours for $42 \%$ of the participants and 6 to 8 hours for $38 \%$. While $61 \%$ of the participants often or almost always work Saturdays, it is very rare that participants work on Sundays, which is due to the German laws regarding shop opening times [12].

The retail chain participating in this study uses a flexible shift system which takes the desired working time of the employees into account. $84 \%$ of the participants state that their requests for certain working times are always or almost always taken into account. Changes of the scheduled working times at short notice occur sometimes for $46 \%$ of the participants and only rarely or not at all for $44 \%$ of them. However, $78 \%$ of the participants state that changes at short notice would only bother them a little or not at all. The participants' satisfaction with their own working time is high, but their satisfaction with their own working time as to their compatibility with their partners' working time is only medium.

Thus, the working-time model has obviously proven its value. Altogether, the retail chain participating in this study can only be regarded as one example. An earlier employee survey in other retail stores using SALSA (cf. for instance [18, pp. 73]) yielded different and in part considerably more negative findings. One can therefore conclude that the results of this study concerning the strains on employees are not representative for the whole retail sector.

\section{Cluster analysis}

\subsection{Cluster analysis methodology}

In order to survey what employees spend their time on, the participants were presented with a number of question items asking them to provide answers on how they use their time in their private lives. It should be noted that the activities were divided up into daily and weekly activities. Furthermore, the participants were asked to state their preferences concerning their activities in their private lives. The employees could then use a weekly schedule which was subdivided into days and individual hours to record the conflicts that would occur if they had to work at a given time interval. These data collected from the retail store employees were used for a cluster analysis; however, so far only the questions concerning the use of time have been taken into account.

Several questions relating to daily and weekly activities in the private sphere of live were asked; for instance, how many hours per day were spent on the following activities: relationship (maintaining the current relationship or looking for a new partner), child care, caring for a relative, caring for pets, driving to work (there and back), media consumption (for instance newspapers, magazines, books, television, DVDs, computer) and sleeping.

In addition, the participants were asked how many hours per week they spent on the following activities: supplemental income sidelines, volunteer work (for instance clubs, volunteer fire department, church, political party, community), housework (such as shopping, cooking, laundry, doing the dishes, tidying, cleaning, gardening), manual labour around the house (for instance renovating and home improvements, building a house), seeing friends or keeping in touch with them, further education, sports/fitness, hobbies and wellness, as well as pursuing religious and spiritual interests.

The k-means methodology [1, pp. 299] was used to cluster this use of time in the private sphere of the employees' lives. This relatively common procedure of deterministic cluster analysis was chosen over others because it allows the formation of nonoverlapping clusters. In this technique, the cluster centres are calculated in such a way that the total 
within-cluster sum of squares is minimised. This is achieved through a three-step, iterative algorithm: (1) based on a predetermined initial partition for the start values of the cluster centres, the classification objects are assigned to the cluster centres in such a way that (2) the cluster sum of squares is minimised (3). The cluster centres are then recalculated. This iteration is stopped as soon as the modification of the cluster centres no longer changes the allocation of the classification objects [1, p. 300]. To use the k-means procedure, however, three conditions must be met:

- Firstly, the classification variables must have the same level of measurement and the same scale length (cf. [1, pp. 175]). To achieve a uniform level of measurement, the scales were standardised via a z-transformation. Here, the raised crucial factor is determining on which measure of distance or similarity the clustering should be based. Since the question items are of mixed types, the squared Euclidian distance was used as measure of (dis-) similarity.

- Secondly, the number of clusters must be known beforehand. In order to find out the optimal number of clusters, test statistics described, among others, by [1, pp. 305] and [15, pp. 129] were used. The criteria explained variance $\left(\eta^{2}\right)$, relative improvement of the explanation of the variance (PREcoefficient) and best variance ratio ( $F_{\max }$-statistic) were applied.

- Thirdly, one must state which $k$ objects shall be set as the initial partition of the cluster centres. As the software SPSS [16] was used, the initial value procedure implemented in this software was applied. This algorithm is relatively simple but depends on the order of the objects [1, p. 336]. This is why the procedure was recalculated several times with the classification objects in respectively different order.

\subsection{Results of the cluster analysis}

Out of the 593 questionnaires that were returned from the retail store sample, 403 individual cases could be used for the cluster analysis. Most of the rejected questionnaires had to be excluded as they had not been filled out completely. In addition, there were so few male participants that only the answers of the female participants were used for the cluster analysis. After an outlier analysis through the singlelinkage procedure and a plausibility check [1, pp. 325] further cases had to be excluded.
For an excerpt of the results of the cluster analysis refer to Table 1. As one can see in this table, based on the criteria for determining the number of clusters described above, a solution with 6 clusters is preferable. All three conditions described in chapter 4.1 which have been used to determine the optimal number of clusters lead to this solution. Based on the results, a solution with 11 clusters would have been justifiable as well, however with slightly poorer key figures compared to the 6-cluster solution.

Firstly, it can be noted that the employees are not evenly distributed over the different clusters. Clusters 4 and 5 are about the same size and by far the biggest clusters. Based on their use of their time, the six employee types (clusters) can be characterised as follows:

- Cluster 1: Part-time female employee with relatives to care for. Cluster $1(\mathrm{~N}=16)$ consists on average of older employees; they work part-time and care for their relatives or children.

- Cluster 2: Free-time oriented female employee. The employees in Cluster $2(\mathrm{~N}=31)$ are younger and have their focus on hobbies, wellness and friends.

- Cluster 3: Housewife with children. The women in Cluster $3(\mathrm{~N}=42)$ are of middle years and work part-time. Their focus clearly lies on household and child care; these women have the greatest tendency to do volunteer work.

- Cluster 4: Working mother with children. The employees in Cluster $4(\mathrm{~N}=144)$ are women of middle years whose focus in their free-time is exclusively on child care.

- Cluster 5: Young woman working full-time. The women in Cluster $5(\mathrm{~N}=159)$ are young women without children who work full-time.

- Cluster 6: Young female still at school or university. Cluster $6(\mathrm{~N}=11)$ is made up of young women who work part-time while going to school or university; these women are highly free-time oriented.

As already mentioned above only statements concerning the use of time and biographical data from the employees were used for this cluster analysis. Each cluster can be interpreted clearly and plausibly, without contradictions. As part of a stability check of the cluster solution, the allocation of the cases to the clusters was examined to ensure this was done in a consistent manner. The allocation can be regarded as stable since the cross-classified number of cases [9] matches perfectly in the respective 6-cluster solution. 


\section{Further Research}

So far, only the employees' free-time activities in the private sphere of life have been taken into account. The next step will be to cluster the weekly schedules according to working times preferences. The position of the conflicts between working and private life will then be used to examine the connection between the individual social roles and strains in the spheres of working life and life outside of work, as well as the conflict potential resulting from this. This study shall comprise data from both sexes and different companies in the service sector.

In parallel to the employee survey, a simulation study will be carried out which shall illustrate the effects of different working-time models on work-life balance depending on the social roles identified in the cluster analysis. In this simulation, a real situation will be abstracted and simplified in order to generate a simulation model. The advantages of this simulation study are the (almost) limitless possibilities to vary the parameters of working-time models and to then discover causalities between these parameters and the consequences for the burden on the employees resulting from them. In practice, this is virtually impossible since the deployment of personnel (meaning also the strain on the employees) cannot be varied for study purposes and testing working-time models in practice is often too complex or time-consuming.
For this study the simulation procedure OSimGAM (German acronym for Object simulator for the design of working-time models; [6, p. 160], [21], [22]) developed at the ifab-Institute of Human and Industrial Engineering - shall be used. This facilitates the evaluation of working-time models in an objective manner on a quantitative basis.

OSim-GAM makes it possible to take into account individual working-time preferences during the design process and to evaluate the achievement of both company and, particularly, employee-oriented goals in the course of the evaluation of workinghours models. Currently, the concept of social roles is being incorporated into OSim-GAM. After the analysis of the employee survey is completed, the insights gained will be integrated into OSim-GAM. The result will be a tool to help model and simulate the interdependencies of the spheres of "working life" and "life outside of work", with which it will be possible to comprehensively evaluate working-time models.

Specifically, simulation will be tested in departments whose survey results indicated the presence of significant conflicts. Subsequently, the effects of different working-hours models on worklife balance in relation to the social roles shall be identified using a systematic simulation study.

Furthermore, the modified simulation procedure will be used with project partners on a pilot basis.

Table 1

Employee types in a retail store

\begin{tabular}{|c|c|c|c|c|c|c|c|c|c|c|c|}
\hline \multicolumn{2}{|c|}{ Cluster No. } & Age & $\begin{array}{l}\text { Number } \\
\text { of } \\
\text { children }\end{array}$ & Child care & $\begin{array}{l}\text { Caring for } \\
\text { a relative }\end{array}$ & Sideline & $\begin{array}{l}\text { Volunteer } \\
\text { work }\end{array}$ & Housework & $\begin{array}{l}\text { Contacts. } \\
\text { friends }\end{array}$ & $\begin{array}{l}\text { Further } \\
\text { education }\end{array}$ & Hobbies \\
\hline \multirow{3}{*}{1} & $\mathrm{~N}$ & 16 & 16 & 16 & 16 & 16 & 16 & 16 & 16 & 16 & 16 \\
\hline & Mean & 42.94 & 1.38 & 5.38 & 2.75 & .50 & 1.25 & 19.94 & 2.75 & .89 & 1.50 \\
\hline & Standard deviation & 10.72 & 1.03 & 6.21 & 1.45 & 2.00 & 3.09 & 11.19 & 2.48 & 2.02 & 1.76 \\
\hline \multirow{3}{*}{2} & $\mathrm{~N}$ & 31 & 31 & 31 & 31 & 31 & 31 & 31 & 31 & 31 & 31 \\
\hline & Mean & 29.74 & .39 & .73 & .00 & 3.77 & .16 & 12.97 & 11.47 & 1.88 & 7.68 \\
\hline & Standard deviation & 11.68 & .80 & 1.77 & .00 & 6.90 & .436 & 10.27 & 6.02 & 2.46 & 5.81 \\
\hline \multirow{3}{*}{3} & $\mathrm{~N}$ & 42 & 42 & 42 & 42 & 42 & 42 & $\overline{42}$ & 42 & 42 & 42 \\
\hline & Mean & 41.43 & 2.14 & 7.10 & .00 & 5.79 & 2.12 & 32.60 & 4.06 & .39 & 2.26 \\
\hline & Standard deviation & 5.60 & .72 & 5.39 & .00 & 8.44 & 2.51 & 13. 14 & 3.09 & 1.01 & 2.32 \\
\hline \multirow{3}{*}{4} & $\mathrm{~N}$ & 144 & 144 & 144 & 144 & 144 & 144 & 144 & 144 & 144 & 144 \\
\hline & Mean & 41.27 & 1.67 & 5.67 & .047 & .65 & .28 & 14.98 & 2.99 & .47 & 1.53 \\
\hline & Standard deviation & 8.64 & .70 & 4.51 & .21 & 1.85 & .628 & 9.12 & 2.48 & .958 & 1.70 \\
\hline \multirow{3}{*}{5} & $\mathrm{~N}$ & 159 & 159 & 159 & 159 & 159 & 159 & 159 & 159 & 159 & 159 \\
\hline & Mean & 25.53 & .01 & .07 & .05 & 1.00 & .64 & 6.81 & 4.14 & 1.35 & 1.69 \\
\hline & Standard deviation & 6.61 & .11 & .62 & .19 & 2.28 & 1.35 & 4.71 & 3.26 & 2.21 & 1.72 \\
\hline \multirow{3}{*}{6} & $\mathrm{~N}$ & 11 & 11 & 11 & 11 & 11 & 11 & 11 & 11 & 11 & 11 \\
\hline & Mean & 21.91 & .00 & .00 & .00 & 5.64 & 1.27 & 7.56 & 11.27 & 25.18 & 6.36 \\
\hline & Standard deviation & 4.42 & .00 & .00 & .00 & 8.10 & 2.00 & 11.05 & 8.55 & 9.01 & 7.67 \\
\hline \multirow{3}{*}{ Total } & $\mathrm{N}$ & 403 & 403 & 403 & 403 & 403 & 403 & 403 & 403 & 403 & 403 \\
\hline & Mean & 33.73 & .91 & 3.06 & .14 & 1.69 & .67 & 13.43 & 4.42 & 1.61 & 2.27 \\
\hline & Standard deviation & 11.11 & 1.03 & 4.53 & .62 & 4.36 & 1.51 & 11.43 & 4.25 & 4.57 & 3.15 \\
\hline
\end{tabular}




\section{References}

[1] J. Bacher et al., Clusteranalyse, Oldenbourg, München, 2010.

[2] H. Bertram and C. K. Spieß, Elterliches Wohlbefinden, öffentliche Unterstützung und die Zukunft der Kinder - der Ravensburger Elternsurvey, Stiftung Ravensburger Verlag, Ravensburg, 2010.

[3] U. Bosshammer, REWE bietet individuelle Zeiteinteilung, Lebensmittel Zeitung, December 10, 2010, p. 48.

[4] Bundesministerium für Familie, Senioren, Frauen und Jugend (ed.), Familienbewusste Arbeitszeiten - Leitfaden für die praktische Umsetzung von flexiblen, familienfreundlichen Arbeitszeitmodellen, Publikationsversand der Bundesregie-

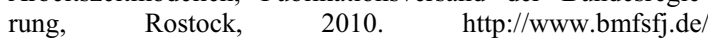
RedaktionBMFSFJ/Broschuerenstelle/Pdf-Anlagen/ Familienbewusste-Arbeitszeiten-Leitfaden, accessed 28.07.2011.

[5] Bundesministerium für Familie, Senioren, Frauen und Jugend (ed.), Charta für familienbewusste Arbeitszeiten. Berlin, February 8, 2011. http://www.erfolgsfaktor-familie.de/data/ downloads/webseiten/Charta_\%20Initiative_Familienbewusste Arbeitszeiten.pdf, accessed: 28.07.2011.

[6] $\bar{T}$. Bogus, Simulationsbasierte Gestaltung von Arbeitszeitmodellen in Dienstleistungsbetrieben mit kundenfrequenzabhängigem Arbeitszeitbedarf, Shaker Verlag, Aachen, 2002.

[7] D. S. Carlson, K. M. Kachmar and L. J. Williams, Construction and Initial Validation of a Multidimensional Measure of Work-Family Conflict, Journal of Vocational Behavior, 56:2 (2002), 249-276.

[8] M. Conlin, Smashing The Clock, BusinessWeek, December 11, 2006. http://www.businessweek.com/print/magazine/ content/06 50/b4013001.htm?chan=gl, accessed: 28.07.2011.

[9] J. L. Fleiss, Statistical methods for rates and proportions, Wiley, New York, NY, et al., 1981.

[10]J. Giertz, Arbeitgeber buhlen um Fachkräfte mit Familie, Financial Times Deutschland, February 7, 2011. http://www.ftd.de/karriere-management/management/:neuearbeitszeitmodelle-arbeitgeber-buhlen-um-fachkraefte-mitfamilie/60008643.html, accessed: 28.07.2011.

[11]P. Knauth, Arbeitszeitflexibilisierung aus arbeitswissenschaftlicher Sicht, in: Arbeitszeitflexibilisierung im Dienstleistungsbereich, G. Zülch, P. Stock and T. Bogus, eds., Shaker Verlag, Aachen, 2002, pp. 51-74.

[12] LadschlG, Gesetz über den Ladenschluss, decreed on November 28, last modified on October 31, 2006

[13] S. Meise, Spielräume, brand eins, 11:12 (2010), pp. 80-83

[14]M. Rimann and I. Udris, Fragebogen "Salutogenetische Subjektive Arbeitsanalyse" (SALSA), in: Handbuch psychologischer Arbeitsanalysen, H. Dunckel, ed., vdf Hochschulverlag an der ETH, Zürich, 1999, pp. 404-419.

[15]C. Schendera, Clusteranalyse mit SPSS, Oldenbourg, München, 2010.

[16] SPSS, Version 18, IBM Deutschland, Ehningen, 2009

[17] Statistisches Bundesamt Deutschland (ed.), Statistisches Jahrbuch 2010 für die Bundesrepublik Deutschland, Bonifatius, Paderborn, 2010.

[18]P. Stock, T. Bogus and S. Stowasser, Auswirkungen flexibler Arbeitszeitmodelle auf den Personaleinsatz und die Belastung des Personals, Shaker Verlag, Aachen, 2004.

[19] Trumpf (ed.), Arbeitszeiten maßgeschneidert - TRUMPF mit innovativem Zeitmodell, Ditzingen, May 18, 2011. http://www.de.trumpf.com/presse/pressemitteilungen/ pressemitteilung/rec-uid/60668.html, accessed: 28.07.2011.

[20] G. Zülch, P. Stock, D. Schmidt and M. Leupold, Conflicts between professional and private life in the different life stages, in: Download Papers, 1st European FEES Conference on Ergonomics, 10-12 October 2010, Bruges, Belgium, Federation of the European Ergonomic Societies (FEES), ed., Medicongress, Assenede, 2010. http://www.ece2010.be/ papers/download.php?f=./poster_papers/P14\%20-\%20Zuelch. pdf, accessed: 18.12.2010.

[21]G. Zülch, J. Fischer and U. Jonsson, An integrated object model for activity network based simulation, in: Proceedings of the 2000 Winter Simulation Conference, Volume 1. J. A Joines, R. R. Barton, K. Kang and P. A. Fishwick, eds., The Institute of Electrical and Electronics Engineers, Piscataway NJ, Association for Computing Machinery; New York, NY, The Society for Computer Simulation International, San Diego, CA, 2000, pp. 371-380.

[22] G. Zülch, U. Jonsson and J. Fischer, Hierarchical simulation of complex production systems by coupling of models, International Journal of Production Economics, 77:1 (2002), 39-51.

[23]G. Zülch, P. Stock, D. Schmidt, and M. Leupold, Conflicts between Work and Private Life Caused by Working Times, in: Human Factors in Organisational Design and Management X, Volume 1, M. Göbel, C. J. Christie, S. Zschernack, A. I. Todd and M. Mattison, IEA Press, Santa Monica, CA, 2011, pp. I-159- I-164. 